\title{
Suicide in female nurses in England and Wales
}

\author{
K. HAWTON, ${ }^{1}$ S. SIMKIN, J. RUE, C. HAW, F. BARBOUR, A. CLEMENTS, \\ C. SAKAROVITCH AND J. DEEKS \\ From the Centre for Suicide Research, University of Oxford, Department of Psychiatry, Warneford Hospital, \\ Oxford
}

\begin{abstract}
Background. Female nurses appear to have an increased risk of suicide but the reasons are unknown.

Method. We have concluded a study of nurse suicides $(N=106)$ in England and Wales, including a psychological autopsy study $(N=42)$ and case-control comparison with living nurses $(N=84)$.

Results. Nearly three-quarters of the nurse suicides had previous contact with psychiatric services and almost half had been psychiatric in-patients in the past. There were particularly marked differences between the cases and controls for current psychiatric disorder $(90.5 \%$ v. $7 \cdot 1 \%$, OR $=$ $68 \cdot 5)$, personality disorder $(38 \cdot 1 \% v \cdot 1 \cdot 2 \%, \mathrm{OR}=32)$, and history of deliberate self-harm $(71 \cdot 4 \%$ v. $2 \cdot 4 \%, \mathrm{OR}=58 \cdot 5$ ). Family background and social factors (especially concerning interpersonal relationships) also distinguished the two groups. Smoking and serious alcohol abuse were much more frequent in the suicides. There was some indication that while many of the suicides were in contact with psychiatric services, care may not have been optimal in some cases.
\end{abstract}

Conclusions. The most important strategies for suicide prevention in nurses are in prevention, detection and management of psychiatric disorders. In assessing suicide risk a history of DSH and the presence of comorbid psychiatric and personality disorders are particularly important.

\section{INTRODUCTION}

In several countries female nurses appear to have an increased risk of suicide compared with many other occupational groups (Hawton \& Vislisel, 1999). On the basis of proportional mortality ratios in England and Wales, female nurses have for several years featured among the occupational groups with an elevated risk of suicide (Kelly et al. 1995; Kelly \& Bunting, 1998). The reasons for this are unknown as no in-depth studies appear to have been conducted (Hawton \& Vislisel, 1999). Ready access to means for suicide, especially drugs for selfpoisoning, has been suggested as one factor (Kelly et al. 1995). Longitudinal studies of large series of nurses in the USA suggested smoking was associated with increased risk (Hemenway et al. 1993) and relatively high caffeine intake

1 Address for correspondence: Professor Keith Hawton, Centre for Suicide Research, University Department of Psychiatry, Warneford Hospital, Oxford OX3 7JX with reduced risk (Kawachi et al. 1996). Given the large proportion of suicides in general in which affective disorders (Lönnqvist, 2000) and substance (especially alcohol) abuse (Murphy, 2000) are diagnosed in psychological autopsy studies, and reports suggesting that both may be common in nurses (reviewed by Hawton \& Vislisel, 1999), one might expect both to be significant risk factors for suicide in nurses.

We have conducted a psychological autopsy study of a series of nurses in England and Wales who died by suicide, including a case-control investigation to identify risk factors.

\section{METHOD}

\section{Subjects}

The potential sample for the study included female nurses in England and Wales who died between January 1994 and December 1997 and received a coroner's inquest verdict of suicide or an open verdict ('undetermined cause'). These 
deaths were notified to the research team by the Office for National Statistics (ONS). Some deaths in 1997 for which the registration with ONS was delayed could not be included.

\section{Sources of information}

Death certificates provided basic demographic information, the cause of death and the name of the coroner who presided over the inquest. Coroners were asked to supply copies of Notes of Evidence from the inquest and pathology reports. General practitioners were contacted through the local Family Health Service Authority and asked to send or allow access to clinical notes and complete a brief questionnaire about each nurse's medical history and contact with the practice. Where relevant, psychiatric casenotes were also requested. Where an open verdict had been recorded all the available information was reviewed and a rating of the likelihood of suicide made at a consensus meeting of the research team, those cases with moderate or high likelihood of suicide being included in the remainder of the investigation. The focus of the study was working nurses so interviews were not sought with the families of nurses who were described as 'retired' on their death certificates. For the rest of the sample, coroners and general practitioners were asked to either provide the name and address of a suitable relative or friend so that they could be approached by the research team to request an interview, or to pass on to such individuals a letter describing the study and requesting an interview. All relatives who were contacted were offered our Bereavement Information Pack (Hill et al. 1997), which provides information about bereavement following suicide, recommended reading material and sources of support.

\section{Definition of nurses}

The population used in estimating suicide risk in nurses in England and Wales (Kelly et al. 1995; Kelly \& Bunting, 1998) included all individuals whose occupation was recorded as 'nurse' (or equivalent) on their death certificates. We therefore included nurses of all kinds in the study, except nursery nurses. Thus, nursing assistants and dental nurses were potential subjects as well as all fully registered nurses in NHS and private health care. Student nurses were also included.

\section{Control nurses}

Identification of matched control nurses was done with the assistance of the Royal College of Nursing and Unison (the public service union). We aimed to obtain two controls for each suicide for whom an informant interview had been conducted. We supplied details of the age, speciality and seniority of the nurse suicides and these organizations identified potential control nurses from their lists of registered members in England and Wales. Matching was by age within 5 years initially (this was subsequently extended to 10 years because of difficulty obtaining sufficient controls in the narrower age band), speciality and seniority. We approached the first two controls for each suicide case by letter, inviting them to participate in the study. Where a potential control nurse declined or it was not possible either to contact her or get a response (after two letters) we approached the next person on the list.

\section{Interviews and data collection}

Interviews were obtained from informants for the suicides and from the controls themselves. Informants for the suicides were seen by F. B., A. C., J. R. or S. S. at home. They were interviewed using a semi-structured schedule which covered the circumstances of the death, personal and family history, social circumstances and problems faced at work and home in the year before the death. An instrument to assess mental state based on ICD-10 research criteria (WHO, 1993), which had been devised by the research team for similar investigations (Hawton et al. 1998) was used. The Personality Assessment Schedule (Tyrer et al. 1988), adapted by the original authors for ICD-10, was used to identify personality disorder and traits. A followup telephone call was made 1 month later to assess the informants' reaction to the study. Information from all sources was collated for each suicide subject and reviewed by at least two members of the research team where there was any ambiguity in the data.

The controls themselves were interviewed because we were aware that the response rate would have been very small if we had asked them for permission to approach relatives or other informants for interview. For the controls the sole source of information was the interview, 
except in two cases where psychiatric casenotes were obtained.

A summary of each interview for the suicides and the controls was reviewed by the whole research team and consensus ratings made for psychiatric disorder and problems the individuals had been facing. A recent diagnosis given by a psychiatrist in the medical records was accepted even if symptoms were not described in detail. A problem was defined as a factor causing difficulties or distress to the person in the year before death. The research team rated the extent of the influence each type of problem appeared to have had in leading to the suicide. The procedure is described in greater detail elsewhere (Hawton et al. 1998). Finally, we noted any factors which the research team thought might have helped prevent each suicide.

The study had the approval of the Oxford Psychiatric Research Ethics Committee. We also informed the Coroners' Society for England and Wales of the project at its outset.

\section{Statistical analyses}

The analyses were conducted using the STATA Statistical Package (StataCorp, 1999) and SPSS Version 9 for Windows (SPSS Inc., 1999). Estimates of the effects of risk factors for suicide in the case-control study were calculated using conditional logistic regression analyses. This technique takes account of the matching of pairs of controls to cases, and estimates the effect of the risk factor as an odds ratio. In this analysis these values can be interpreted as approximate risk ratios. Estimates of the odds ratios are quoted with $95 \%$ confidence intervals.

Where data were missing on a case the corresponding controls were also removed from the analysis, in order to retain the power of the matching. If data for a single control was missing, the remaining control was retained in the analysis. Where either no cases or no controls reported the risk factor, Fisher's exact test was used to test the significance of the difference in proportions with the risk factor as a matched conditional analysis was not possible.

Caution was exercised in investigating the joint effects of risk factors on suicide in multivariate models. Several of the variables in the analysis were very strongly correlated with each other, and the impact of the inclusion of additional variables in the model on the stability of risk factor estimates was examined for evidence of problems introduced through colinearity.

Information was missing for some subjects on some variables and in analysing and presenting these results the denominators have been altered accordingly.

\section{RESULTS}

\section{Samples of nurse suicides}

We were supplied with the death certificates of 155 females who died during the study period, whose occupation was recorded as 'nurse' or equivalent (e.g. 'district nurse', 'hospital ward sister', 'nurse tutor', 'nursing auxiliary'), and whose deaths received a suicide or open verdict. We excluded 49 of these because after further enquiry we found that 27 had not worked as nurses within the 5 years before death, 19 were never nurses, two were from abroad and had not worked in the UK, and one case was probably a murder. The final sample was therefore 106 cases. Sixty-nine $(65 \cdot 1 \%)$ of the deaths had received a coroner's verdict of suicide and 37 $(34.9 \%)$ an open verdict.

We obtained an interview with an informant in $42(39.6 \%)$ of the 106 suicide cases. The reasons for not obtaining interviews in the remaining 64 cases were informant refusal (23), no response from informant (22), no informant identified (15) and coroner refused permission to approach an informant (4). For the 65 cases where it was possible to contact an informant, interviews were obtained for $64.6 \%$. The relationships of the informants to the deceased were: husband or partner (16), parent(s) (14), sibling (6), friend (4), daughter (2) and psychiatrist (2). In two cases informants from two of these categories were interviewed. In total, 50 informants were interviewed. The interviews took place between 4 and 52 months (median $17 \cdot 5$ months) following the deaths.

We were able to obtain full coroners' inquest information in $88(83.0 \%)$ and general practitioner records in $87(82.1 \%)$ of the suicide cases. In three cases $(2.8 \%)$ neither the coroners' records nor general practitioner records were obtainable. Psychiatric casenotes were obtained in 59 cases and general hospital records in five.

The nurse suicides for whom an informant interview was obtained showed some differences 
from the remainder of the suicides. Interviews were obtained for 22 out of $34(64.7 \%)$ staff nurses/SRNs, whereas no informant interviews were possible for the 11 SEN nurses. We were also unable to obtain interviews for any of the three student nurses, in two cases because the coroner denied us access to relatives.

\section{Control nurses}

In obtaining two matched control nurses for each suicide with an informant interview, we often had to approach several nurses before two agreed to participate in the study. The first two control nurses agreed to participate in five cases. In 10 cases we had to approach an extra nurse. In 10 cases we approached four nurses, in 13 cases between five and 10 nurses were approached, and in four cases we had to approach more than 10 nurses. In many of the cases where we had to approach extra potential controls we had received no reply to our letters of invitation to earlier nurses or, in some cases, the wrong address had been supplied.

Table 1. Demographic and employment characteristics of the nurse suicides $(\mathrm{N}=106)$

\begin{tabular}{|c|c|c|}
\hline & $N$ & $(\%)$ \\
\hline \multicolumn{3}{|l|}{ Age, years } \\
\hline $20-34$ & 42 & $(39 \cdot 6)$ \\
\hline $35-49$ & 51 & $(48 \cdot 1)$ \\
\hline $50-59$ & 13 & $(12 \cdot 3)$ \\
\hline \multicolumn{3}{|l|}{ Marital status } \\
\hline Single & 39 & $(36 \cdot 8)$ \\
\hline Married & 30 & $(28 \cdot 3)$ \\
\hline Divorced/separated & 35 & $(33 \cdot 0)$ \\
\hline Widowed & 2 & $(1.9)$ \\
\hline \multicolumn{3}{|l|}{ Nursing speciality } \\
\hline Geriatrics & 16 & $(15 \cdot 1)$ \\
\hline General (not specified) & 13 & $(12 \cdot 3)$ \\
\hline General medical & 12 & $(11 \cdot 3)$ \\
\hline Psychiatry & 10 & $(9 \cdot 4)$ \\
\hline Dental & 6 & $(5 \cdot 7)$ \\
\hline District nurse/health visitor & 5 & $(4 \cdot 7)$ \\
\hline General surgical & 4 & $(3 \cdot 8)$ \\
\hline Other & 26 & $(24 \cdot 5)$ \\
\hline Not known & 14 & $(13 \cdot 2)$ \\
\hline \multicolumn{3}{|l|}{ Nursing grade } \\
\hline Matron/manager & 5 & $(4 \cdot 7)$ \\
\hline Nursing officer & 2 & $(1.9)$ \\
\hline Charge nurse/sister/assistant matron & 11 & $(10 \cdot 4)$ \\
\hline Health visitor/district nurse/practice nurse & 6 & $(5 \cdot 7)$ \\
\hline Staff nurse/SRN & 34 & $(32 \cdot 1)$ \\
\hline SEN & 11 & $(10 \cdot 4)$ \\
\hline Assistant/auxiliary nurse & 17 & $(16 \cdot 0)$ \\
\hline Student/trainee & 3 & $(2 \cdot 8)$ \\
\hline Other & 7 & $(6 \cdot 6)$ \\
\hline Not known & 10 & $(9 \cdot 4)$ \\
\hline
\end{tabular}

\section{Characteristics of the nurses who died by suicide}

\section{General characteristics}

The demographic and occupational characteristics of the full sample of 106 nurses who died by suicide are shown in Table 1.

\section{Methods used for suicide}

The method of suicide was self-poisoning in 72 $(67 \cdot 9 \%)$ cases, self-injury in $32(30 \cdot 2 \%)$ and both methods in two $(1.9 \%)$. Comparison of the methods used for suicide by the nurses with those of other females in the same age range in England and Wales during the study period, using ICD groupings, showed that poisoning with drugs was only a little more common in the nurses $(61 / 106,57 \cdot 6 \%$, v. $1558 / 3171,49 \cdot 1 \%$; $\left.x^{2}=2 \cdot 91, P=0.09\right)$. The frequency of other methods of suicide was similar in the two groups.

Antidepressants (28 cases) and non-opiate analgesics ( 21 cases) were the most common drugs involved in self-poisoning. Of the latter, 16 $(76.2 \%)$ involved co-proxamol or its equivalent (i.e. paracetamol plus dextropropoxyphene). Opiates were involved in 12 self-poisoning deaths. Insulin was used in three cases and an anaesthetic agent in one. In all four cases this medication had been taken from the nurse's workplace. Hanging (18 cases) was by far the most frequent method of self-injury.

\section{Psychiatric history}

Contact with psychiatric services (at any time in the past) had occurred in 69/97 (71.1\%) nurses for whom this information was available. At least 52 had been psychiatric hospital in-patients. Of 101 cases for whom there was information on psychiatric care at the time of death, $46(45.5 \%)$ were in contact with psychiatric services. Nine $(8.9 \%)$ were psychiatric hospital in-patients.

\section{Previous deliberate self-harm}

Information on previous deliberate self-harm (DSH; ' attempted suicide') was available for 99 cases. Of these, $63(63.6 \%)$ had a known history of DSH, of whom $38 / 60(63 \cdot 3 \%)$ were known to have engaged in multiple episodes. The timing of the most recent previous episode was known in 59 cases: in $12(20 \cdot 3 \%)$ this had occurred within a month of death, in $22(37.3 \%)$ during the remainder of the year beforehand, $13(22 \cdot 0 \%)$ 
Table 2. Psychiatric disorder at the time of death in the nurse suicides and at the time of interview in the control nurses

\begin{tabular}{lccc}
\hline \hline & \multicolumn{2}{c}{ Nurse suicides } \\
\cline { 2 - 3 } & $\begin{array}{c}\text { With psychological autopsy } \\
\text { interview } \\
(N=42)^{*}\end{array}$ & $\begin{array}{c}\text { Without psychological } \\
\text { autopsy interview } \\
(N=50) \dagger\end{array}$ & $\begin{array}{c}\text { Control nurses } \\
(N=84) \ddagger\end{array}$ \\
Psychiatric disorder & $N(\%)$ & $N(\%)$ & $6(7 \cdot 1)$ \\
ICD-10 classification) & $34(81 \cdot 0)$ & $27(54 \cdot 0)$ & 0 \\
\hline Affective disorders F30-39 & 2 & 2 & 4 \\
Bipolar (F31) & 31 & 3 & 2 \\
Depressive episode (F32) & 1 & $3(6 \cdot 0)$ & 0 \\
Recurrent depressive disorder (F33) & $8(19 \cdot 0)$ & 0 & 0 \\
Substance abuse: alcohol F10 & 2 & 3 & 0 \\
Alcohol harmful use (F10.1) & 6 & $9(18 \cdot 0)$ & 0 \\
Alcohol dependence (F10.2) & $1(2 \cdot 4)$ & 3 & 0 \\
Substance abuse: drugs F11-19 & 0 & 6 & $4(4 \cdot 8)$ \\
Drug harmful use (F11.1-19.1) & 1 & $3(6 \cdot 0)$ & 0 \\
Drug dependence (F11.2-19.2) & $4(9 \cdot 5)$ & 2 & 0 \\
Neurotic, stress-related and somatoform disorders F40-48 & 1 & 0 & 3 \\
Anxiety disorder (F40-41) & 1 & 0 & 0 \\
Obsessive-compulsive disorder (F42) & 1 & 1 & 0 \\
Post-traumatic stress disorder (F43.1) & 1 & $1(2.0 \%)$ & 0 \\
Somatoform disorder (F45) & 0 & 1 & 0 \\
Eating disorders F50 & 0 & $2(4 \cdot 0)$ & 0 \\
Bulimia nervosa (F50.2) & $3(7 \cdot 1)$ & 1 & 0 \\
Schizophrenia and non-affective psychoses F20-29 & 0 & 0 & 0 \\
Paranoid schizophrenia (F20.0) & 1 & 1 & \\
Hebephrenic schizophrenia (F20.1) & 1 & & 0 \\
Post-schizophrenic depression (F20.4) & 1 & & 0 \\
Unspecified non-organic psychosis (F29) & & & 0 \\
\hline \hline
\end{tabular}

* Multiple disorders were recorded in 12 cases.

$\dagger$ There was no information on psychiatric disorder for 14 subjects without an informant interview. Multiple disorders were recorded in seven cases.

$\$$ Multiple disorders were recorded in two cases.

between $>1$ and $\leqslant 5$ years beforehand, and 12 $(20 \cdot 3 \%)>5$ years previously.

\section{General practitioner contact}

One hundred and four nurses were known to have been registered with a general practitioner. The timing of the most recent contact was known in 96 cases. This contact was within a week of death in $16(16.7 \%)$ cases, within $>1$ week to 1 month in $29(30 \cdot 2 \%)$, and within $>1$ month to 3 months in $24(25.0 \%)$. The reason for the most recent general practitioner consultation was known in 95 cases. This was for emotional problems in $52(54.7 \%)$, physical health in $37(38.9 \%)$ and both reasons in six $(6 \cdot 3 \%)$. Twenty individuals were known to have been receiving treatment for psychiatric problems from their general practitioners (only) at the time of death.

\section{Psychotropic medication}

Of 99 nurses whose medication status at the time of death was known, $61(61 \cdot 6 \%)$ were receiving prescriptions for psychotropics. Antidepressants were being prescribed in 51 cases, minor tranquillizers or hypnotics in 13 and major tranquillizers in 13. Of those on antidepressants where the dose was known $(N=45), 33(73 \cdot 3 \%)$ were prescribed the equivalent of at least $125 \mathrm{mg}$ amitriptyline per day. Only three were prescribed the equivalent of $<75 \mathrm{mg}$.

\section{Physical health}

There was a known physical health problem at the time of death in $27 / 101(26 \cdot 7 \%)$ cases. The most common problems involved pain, mostly due to musculoskeletal disorders. Six nurses had asthma and four epilepsy.

\section{Current psychiatric disorder}

As shown in Table 2, in the 42 nurse suicides where an interview with an informant was conducted, $38(90 \cdot 5 \%)$ had a current psychiatric 
Table 3. Background and sociodemographic characteristics of nurse suicides and controls

\begin{tabular}{|c|c|c|c|c|c|c|c|}
\hline & \multicolumn{2}{|c|}{ Suicides $(N=42)$} & \multicolumn{2}{|c|}{ Controls $(N=84)$} & \multirow{2}{*}{$\begin{array}{l}\text { Odds } \\
\text { ratio }\end{array}$} & \multirow[b]{2}{*}{$(95 \% \mathrm{CI})$} & \multirow[b]{2}{*}{$P$} \\
\hline & $N$ & $(\%)$ & $N$ & $(\%)$ & & & \\
\hline $\begin{array}{l}\text { Death of parent before } \\
\text { age } 16 \text { years }\end{array}$ & 7 & $(16 \cdot 7)$ & 7 & $(8 \cdot 3)$ & $2 \cdot 13$ & $(0 \cdot 71,6 \cdot 43)$ & $0 \cdot 18$ \\
\hline $\begin{array}{l}\text { Parental separation/divorce } \\
\text { before age } 16 \text { years }\end{array}$ & 7 & $(16 \cdot 7)$ & 8 & $(9 \cdot 5)$ & $1 \cdot 83$ & $(0 \cdot 63,5 \cdot 29)$ & $0 \cdot 3$ \\
\hline $\begin{array}{l}\text { Did not live with both } \\
\text { parents before up to age } \\
16 \text { years }\end{array}$ & 13 & $(31 \cdot 0)$ & 15 & $(17 \cdot 9)$ & 1.93 & $(0 \cdot 85,4 \cdot 40)$ & $0 \cdot 12$ \\
\hline Suicide/DSH in parent or sibling & 4 & $(10 \cdot 0)$ & 10 & $(11 \cdot 9)$ & $1 \cdot 00$ & $(0 \cdot 29,3 \cdot 50)$ & $1 \cdot 0$ \\
\hline $\begin{array}{l}\text { From a medical/nursing } \\
\text { family background }\end{array}$ & 19 & $(45 \cdot 2)$ & 35 & $(41 \cdot 7)$ & $1 \cdot 15$ & $(0 \cdot 55,2 \cdot 42)$ & $0 \cdot 7$ \\
\hline $\begin{array}{l}\text { Years worked as a nurse } \\
\qquad \begin{array}{l}1-5 \\
6-10 \\
11-20 \\
\geqslant 21\end{array}\end{array}$ & $\begin{array}{r}10 \\
11 \\
15 \\
6\end{array}$ & $\begin{array}{l}(23 \cdot 8) \\
(26 \cdot 2) \\
(35 \cdot 7) \\
(14 \cdot 3)\end{array}$ & $\begin{array}{r}8 \\
22 \\
44 \\
10\end{array}$ & $\begin{array}{l}(9 \cdot 5) \\
(26 \cdot 2) \\
(52 \cdot 4) \\
(11 \cdot 9)\end{array}$ & $0 \cdot 90^{*}$ & $(0 \cdot 80,1 \cdot 00)$ & $0 \cdot 04$ \\
\hline Not married & 31 & $(73 \cdot 8)$ & 36 & $(42 \cdot 9)$ & $3 \cdot 32$ & $(1 \cdot 51,7 \cdot 30)$ & $0 \cdot 003$ \\
\hline No children & 23 & $(54 \cdot 8)$ & 31 & $(36 \cdot 9)$ & $2 \cdot 25$ & $(1 \cdot 00,5 \cdot 05)$ & $0 \cdot 05$ \\
\hline Not living in own home & 18 & $(42 \cdot 9)$ & 18 & $(21 \cdot 4)$ & $2 \cdot 22$ & $(1 \cdot 09,4 \cdot 53)$ & $0 \cdot 03$ \\
\hline Living alone & 16 & $(38 \cdot 1)$ & 11 & $(13 \cdot 1)$ & $5 \cdot 59$ & $(1 \cdot 82,17 \cdot 2)$ & $0 \cdot 003$ \\
\hline$\geqslant 2$ moves in last 5 years & 20 & $(47 \cdot 6)$ & 12 & $(14 \cdot 3)$ & $6 \cdot 37$ & $(2 \cdot 34,17 \cdot 3)$ & $<0.001$ \\
\hline No confidant & $3 \dagger$ & $(7 \cdot 5)$ & 0 & $(0)$ & $\infty$ & - & $0 \cdot 03$; \\
\hline
\end{tabular}

disorder compared with only six $(7 \cdot 1 \%)$ of the 84 controls (the disorders of the two controls who had a diagnosis of recurrent depressive disorder were in remission at the time of interview). Affective disorders were by far the most frequent diagnoses in the nurse suicides, followed by alcohol abuse disorders. In the nurses for whom an interview with an informant was not possible, $37(74.0 \%)$ were given a psychiatric diagnosis. This is likely to be an underestimate. This group included a substantial number of nurses with disorders related to drug abuse.

Co-morbidity of psychiatric disorders was present in $12(28.6 \%)$ of the suicides for whom an informant was interviewed, the most common combination being of affective and alcohol abuse disorders (seven cases). There were two $(2 \cdot 4 \%)$ cases with comorbid diagnoses in the control group.

\section{Personality disorders}

Personality disorders were diagnosed in 16 $(38.1 \%)$ of the suicides for whom an interview was carried out with an informant and only one $(1.2 \%)$ of the controls. Two personality disorder diagnoses were made in five of the suicides. The ICD-10 diagnoses were: paranoid (5); histrionic (3); anankastic (3); emotionally unstable (2); dissocial (1); and unspecified (7). All 16 of the suicides with a personality disorder also had a co-morbid psychiatric disorder. The single control nurse with a personality disorder diagnosis (dependent personality disorder) had no concurrent psychiatric disorder.

\section{Comparison of the nurse suicides (with an informant interview) with the control nurses Background factors}

Somewhat more of the suicides than the controls had lost a parent through death, or experienced parental separation or divorce before they were 16 years old, and fewer had lived with both parents before this age (Table 3). None of these differences, however, were statistically significant. Suicide and deliberate self-harm by parents or siblings had occurred with similar frequency in the two groups. Also, similar proportions 
Table 4. Comparison of nurse suicides and control nurses - psychiatric disorder and DSH

\begin{tabular}{|c|c|c|c|c|c|c|c|}
\hline & \multicolumn{2}{|c|}{ Suicides $(N=42)$} & \multicolumn{2}{|c|}{ Controls $(N=84)$} & \multirow{2}{*}{$\begin{array}{l}\text { Odds } \\
\text { ratio }\end{array}$} & \multirow[b]{2}{*}{$(95 \% \mathrm{CI})$} & \multirow[b]{2}{*}{$P$} \\
\hline & $N$ & $(\%)$ & $N$ & $(\%)$ & & & \\
\hline Psychiatric disorder & 38 & $(90 \cdot 5)$ & 6 & $(7 \cdot 1)$ & $68 \cdot 5$ & $(9 \cdot 40,500)$ & $<0.001$ \\
\hline Personality disorder & 16 & $(38 \cdot 1)$ & 1 & $(1 \cdot 2)$ & 32 & $(4 \cdot 24,241)$ & 0.001 \\
\hline Previous DSH & 30 & $(71 \cdot 4)$ & 2 & $(2 \cdot 4)$ & $58 \cdot 5$ & $(7 \cdot 98,429)$ & $<0.001$ \\
\hline $\begin{array}{l}\text { Past psychiatric disorder } \\
\text { Co-morbidity }\end{array}$ & 33 & $(78 \cdot 6)$ & 37 & $(44 \cdot 0)$ & $4 \cdot 82$ & $(1 \cdot 92,12 \cdot 1)$ & 0.001 \\
\hline Psychiatric disorders & 12 & $(28 \cdot 6)$ & 2 & $(2 \cdot 4)$ & $22 \cdot 5$ & $(2 \cdot 9,173 \cdot 9)$ & 0.003 \\
\hline $\begin{array}{l}\text { Psychiatric and } \\
\text { personality disorders }\end{array}$ & 16 & $(38 \cdot 1)$ & 0 & 0 & $\infty$ & & $<0.001^{*}$ \\
\hline
\end{tabular}

* Fisher's exact test (matched analysis not possible).

were from medical or nursing family backgrounds. The suicides had generally worked for less time in nursing.

\section{Sociodemographic factors}

The suicides were significantly more likely than the controls not to have been married, have children or been living in their own home (Table 3). They were more likely to have been living alone and to have moved house at least twice in the previous 5 years. All the controls and most of the suicides had at least one person they could confide in, but the difference between the suicides and controls was statistically significant.

\section{Psychiatric disorders}

The most marked differences between the nurse suicides and the controls were found for psychiatric disorder at the time of death (or interview), personality disorder and previous $\mathrm{DSH}$, all three of which were much more common in the suicides (Table 4). A past history of psychiatric disorder was also more frequent in the nurse suicides, although a substantial proportion of the controls also had such a history. Thus, a history of DSH is perhaps the most important risk factor because of its very low frequency in the controls. However, many more of the suicides had been psychiatric inpatients $(63.4 \%$ compared with only $2.4 \%$ of the controls), indicating the relative severity of the past psychiatric disorders of nurse suicides. Co-morbidity of psychiatric disorders, and of personality and psychiatric disorders, was also more prevalent in the suicides.

We intended conducting a multivariate analysis of the factors in Table 4 and some other variables for which differences between the groups were found. However, this was not feasible because the very strong inter-relationships between some of the variables (e.g. past psychiatric history, previous DSH, psychiatric disorder) meant that the analysis was unstable.

\section{General practitioner consultations}

Over half of the suicides $(21 / 41,51 \cdot 2 \%)$ had consulted their general practitioners in the month before death compared with just over a quarter $(22 / 83,26.5 \%)$ of the controls (before their interviews) $(\mathrm{OR}=3 \cdot 07,95 \% \mathrm{CI} 1 \cdot 31-7 \cdot 20$, $P=0 \cdot 01)$. The last consultations by the suicides were far more likely to have been for emotional reasons $(27 / 40,67 \cdot 5 \%$ v. $10 / 84,11.9 \%$; OR $=$ $21 \cdot 9,95 \%$ CI $5 \cdot 16-92 \cdot 7, P<0 \cdot 001)$.

\section{Smoking, caffeine and alcohol consumption}

More than half the suicides were smokers compared with just over one in five of the controls (Table 5). Six of the suicides and none of the controls were known to be consuming more than 50 units of alcohol per week; in fact all six suicides were consuming in excess of 100 units. The highest weekly alcohol intake in the controls was 35 units. Caffeine intake (measured by consumption of coffee, cola and tea) was fairly similar in the two groups.

\section{Problems in last year}

Somewhat more of the controls reported occupational problems, although the difference was not statistically significant (Table 5). This finding probably reflects the fact that the controls themselves were interviewed rather than informants. The most common occupational problems in the nurse suicides (with the frequencies for the control nurses shown in brackets) were; 
Table 5. Comparison of nurse suicides and control nurses - smoking, alcohol and caffeine consumption and problems in last year

\begin{tabular}{|c|c|c|c|c|c|c|c|}
\hline & \multicolumn{2}{|c|}{ Suicides $(N=42)$} & \multicolumn{2}{|c|}{ Controls $(N=84)$} & \multirow{2}{*}{$\begin{array}{l}\text { Odds } \\
\text { ratio }\end{array}$} & \multirow[b]{2}{*}{$(95 \% \mathrm{CI})$} & \multirow[b]{2}{*}{$P$} \\
\hline & $N$ & $(\%)$ & $N$ & $(\%)$ & & & \\
\hline \multicolumn{8}{|l|}{ Smoking } \\
\hline $\begin{array}{c}\text { Smoker at time of } \\
\text { death/interview }\end{array}$ & 21 & $(52 \cdot 5)$ & 18 & $(21 \cdot 4)$ & $4 \cdot 37$ & $(1 \cdot 81,10 \cdot 54)$ & $0 \cdot 001$ \\
\hline \multicolumn{8}{|l|}{ Alcohol } \\
\hline $\begin{array}{l}>50 \text { units of alcohol per week } \\
\text { Caffeine consumption }\end{array}$ & 6 & $(17 \cdot 1)$ & 0 & $(0)$ & $\infty$ & & $<0.001^{*}$ \\
\hline $\begin{array}{l}>3 \text { caffeine drinks/day } \\
\text { Problems in past vear }\end{array}$ & 31 & $(83 \cdot 8)$ & 61 & $(72 \cdot 6)$ & $2 \cdot 16$ & $(0 \cdot 80,5 \cdot 83)$ & $0 \cdot 13$ \\
\hline Occupational & 28 & $(66 \cdot 7)$ & 69 & $(82 \cdot 1)$ & $0 \cdot 46$ & $(0 \cdot 20,1 \cdot 05)$ & 0.07 \\
\hline Relationship with partner & 20 & $(47 \cdot 6)$ & 25 & $(29 \cdot 8)$ & $2 \cdot 09$ & $(0 \cdot 98,4 \cdot 47)$ & $0 \cdot 06$ \\
\hline Financial & 12 & $(28 \cdot 6)$ & 7 & $(8 \cdot 3)$ & $4 \cdot 26$ & $(1 \cdot 48,12 \cdot 25)$ & 0.007 \\
\hline Physical health & 10 & $(23 \cdot 8)$ & 14 & $(16 \cdot 7)$ & $1 \cdot 50$ & $(0 \cdot 62,3 \cdot 82)$ & $0 \cdot 3$ \\
\hline Mental health & 38 & $(90 \cdot 5)$ & 11 & $(13 \cdot 1)$ & $61 \cdot 12$ & $(8 \cdot 36,446.99)$ & $<0.001$ \\
\hline
\end{tabular}

* Fisher's exact test (matched analysis not possible).

work overload, $28.6 \%(32.1 \%)$; conflict with colleagues and/or supervisor, $21.4 \%(23.8 \%)$; feeling unsupported, $19 \cdot 1 \% \quad(31.0 \%)$; and having excessive responsibility, $16.7 \%(0)$. Many more of the suicides were having problems with a partner, and more had financial problems. There was little difference between the suicides and controls in the prevalence of physical health problems.

\section{Problems contributing to suicide}

The most common problems thought to contribute to the suicides of the nurses in the psychological autopsy study were mental illhealth (36 cases), difficulties in a relationship with a partner (9), occupational difficulties (8) and alcohol abuse (6).

\section{Factors that might have prevented suicide}

There were several types of factors which the research team thought might have helped prevent the suicides. The largest category, in keeping with the high prevalence of psychiatric disorder, concerned psychiatric care (20 cases). In 11 cases this related to the necessity for more vigorous treatment of already detected psychiatric illness. In nine cases it concerned more general aspects of management, such as better risk assessment, need for (compulsory) admission to hospital, and more intensive or assertive follow-up. In a further three cases the liaison between a psychiatrist and the nurse's general practitioner could have been improved. Inappropriate prescribing was thought to have been an issue in five cases. In two of these it was thought that excessive amounts of co-proxamol had been made available and in two that large amounts of toxic antidepressants had been prescribed (in one case without follow-up being arranged). In four cases it was thought that treatment for alcohol problems should have been provided. Three nurses could have benefited from treatment for depression. In a further four cases it was thought that psychiatric treatment might have been compromised because the individual was a nurse. Examples were where a nurse knew clinicians in the psychiatric service or was reluctant to seek treatment in the area where she worked.

\section{DISCUSSION}

This study is, to our knowledge, the first indepth investigation of suicide in nurses. It was restricted to female nurses because they and not male nurses appear to carry an elevated risk of suicide (Kelly et al. 1995; Kelly \& Bunting, 1998; Hawton \& Vislisel, 1999).

\section{Methodological issues}

The sample of nurses who had died by suicide was derived from information supplied by ONS on the basis of death certificates. Our initial investigation of the original sample showed that the occupational information on the death certificates was misleading in a substantial number of cases, a fact which may undermine 
epidemiological findings regarding occupational risk.

The acceptance rate for informant interviews was modest, partly because potential informants were often not identifiable or we could not get a response from them in spite of making extensive efforts to do so. We may have been given the wrong address for potential informants, or they may have moved away. Where we were able to establish contact with potential informants the response rate was positive in nearly two-thirds.

Despite these problems we were able to obtain extensive information on many nurses where an informant interview was not possible by reviewing records available to us, especially as a large proportion had received psychiatric care. There was some indication from this that drug abuse disorders were more common in the cases without an interview. We cannot, however, interpret the significance of findings which were positive for fewer in the non-interview group compared with those where an interview with an informant was possible, because of the difference in access to information. We have not reported such data.

We collected interview information on the control nurses from the nurses themselves because we were aware that they would often have been reluctant to allow us to interview their relatives or other informants. This would have made collection of control information extremely difficult and highly biased. Our approach means, however, that we had greater access to certain information (e.g. occupational difficulties and family history) in the controls. Thus, findings based on such factors must be interpreted with extreme caution. In this regard it is worth noting that Beautrais and colleagues (1999) have shown that there is relatively good agreement between information provided by informants and serious suicide attempters.

We often had to approach several nurses in order to obtain two interviewed controls for each case. While some potential controls refused, often we did not obtain a response to our letter of invitation or had been supplied with an incorrect address. This might have introduced bias although the direction of this cannot be determined because we had no information on the controls who did not participate except for age, speciality and seniority.

Issues regarding identification of and gaining access to controls in psychological autopsy studies are well recognized. Other limitations of such studies, which we have discussed elsewhere (Hawton et al. 1998), apply equally to this study as to other similar investigations. These include dealing with retrospective information subject to recall bias and the varying quality and quantity of information between subjects.

\section{Methods used for suicide}

The small excess in poisoning by drugs in the nurse suicides compared with female suicides in the general population provides only limited support for the theory that access to or knowledge of means may contribute to suicide risk in nurses, in contrast to the greater use of substances available in clinical settings (e.g. anaesthetic agents and insulin) in suicides by doctors (Hawton et al. 2000). The relatively frequent use of antidepressants for self-poisoning among the nurses may reflect the large proportion who were receiving treatment for depression rather than specific knowledge of the dangers of overdose of some antidepressants. However, the usual dictum of prescribing less toxic antidepressants for people at risk, especially those with a previous history of DSH, applies equally to nurses as to anyone else. The large number of cases in which co-proxamol was used for self-poisoning is a further reminder of the dangers of this drug (Vale et al. 1984).

\section{Psychiatric history}

One of the most striking findings was the high frequency of previous contact with psychiatric services, with nearly three-quarters of the nurse suicides having had psychiatric care. Almost half the sample had been psychiatric in-patients at some time, indicating that the past psychiatric disorders had often been relatively severe. Also nearly half were in contact with psychiatric services at the time of death. This is a much larger proportion than is found for suicides in general as indicated by findings for both genders from the National Confidential Inquiry into Suicide and Homicide by People with Mental Illness (Department of Health, 1999). This may be due to higher rates of depression in females.

Previous DSH was also very common, with nearly two-thirds known to have a history of non-fatal self-poisoning or self-injury. Again, this is a somewhat higher figure than found in 
most psychological autopsy studies (Sakinofsky, 2000), which may reflect the generally higher rate of DSH in females. The majority of those with a history of DSH had engaged in more than one episode, underlining the added suicide risk associated with repetition of DSH (Sakinofsky, 2000).

\section{Psychiatric and personality disorders at the time of death}

Nearly all of the nurses who died by suicide for whom an informant interview was possible had psychiatric disorders at the time of death. Even among the cases without an interview nearly three-quarters had psychiatric disorders and presumably this was an underestimate due to relevant information not being available in some cases. The prevalence of affective disorders in those with an informant interview was extremely high $(81.0 \%)$. In the majority of these the disorders had been recognized and treatment instigated. Where antidepressants had been prescribed, the doses were in most cases of an adequate level. Nevertheless, there appeared to be grounds for more vigorous treatment of psychiatric disorder and management of risk in many cases.

Nearly one in five had alcohol abuse disorders, and in the sample without an informant interview a similar proportion had drug abuse disorders. None of the control group of nurses had these disorders, which highlights the risk associated with substance abuse, especially when it is co-morbid with affective disorder (Murphy, 2000). Inadequate treatment of recognized alcohol abuse was noted in some cases.

Personality disorders were also present in a substantial proportion $(38.1 \%)$ of the nurses who died by suicide, but only one of the controls. It is clear that personality abnormalities make an important contribution to suicide risk in nurses, especially when combined with psychiatric disorders, as much as in other populations (Linehan et al. 2000).

The extent of psychiatric and personality disorders in this study is comparable with that found in two general population psychological autopsy studies from the United Kingdom (Barraclough et al. 1974; Foster et al. 1997).

In a few cases the management of psychiatric disorder may have been compromised by the fact that individuals were nurses. Similar prob- lems have been noted for doctors. It is important that being a clinician should not impede care.

\section{Case-control comparison}

The inclusion of a matched control group, while associated with some methodological problems as noted above, has allowed specific risk factors to be identified. There were clearly very marked differences between the nurse suicides and the controls with regard to psychiatric history, current disorder, co-morbidity and history of DSH. The high prevalence and inter-relationships between these characteristics did not permit a multivariate analysis. However, previous DSH and current psychiatric disorder were clearly major distinguishing factors. Interestingly, previous psychiatric disorder, while differing markedly in frequency between the suicides and the controls, was nonetheless reported by $44 \%$ of the controls. As such it is less helpful in identifying those at risk. A history of DSH, found in $71.4 \%$ of the suicides and only $2.4 \%$ of the controls, is clearly a far more useful risk factor, especially in nurses presenting with a psychiatric disorder.

Social circumstances also distinguished the nurse suicides from the controls. Thus, the nurses who died by suicide were less likely to be married, have children, and be living in their own home, whereas they were more often living alone and had moved home at least twice in the 5 years before death. Somewhat fewer of the suicides had a confidant.

Recent health care contacts were far more frequent in the suicides, mainly because of emotional problems, although the incidence of physical health problems was only slightly greater in the suicides than in the controls.

Smoking was far more common in the suicides $(52.5 \%)$ than the controls $(21.4 \%)$, in keeping with an earlier finding from a longitudinal study of nurses in the USA (Hemenway et al. 1993). We found no evidence that caffeine intake is a factor associated with lower suicide risk, as suggested by another American study (Kawachi et al. 1996). The alcohol intake of the suicides was higher than that of the controls, mainly because of very high alcohol consumption in six of the suicides.

Paradoxically, there appeared to be a somewhat higher incidence of occupational problems in the controls than the suicides which, as noted 
above, probably reflects greater accessibility to this information in the controls. However, occupational problems were common in both groups. Relationship problems and financial difficulties were considerably more frequent in the nurses who died by suicide.

\section{Factors contributing to suicide}

Mental health problems were judged to be by far the most frequent factor contributing to the suicides in the nurses in the psychological autopsy study. However, these would often have been secondary to other factors and in many cases there appeared to be multiple contributory problems, of which relationship difficulties and occupational problems were the next most frequent. Alcohol abuse was judged to be an important contributory factor in more than one in seven cases.

\section{Prevention of suicide in nurses}

The most important strategies for suicide prevention in nurses are likely to be in relation to prevention, detection and management of mental health problems. Clinicians should be aware that the presence of a history of DSH and/or comorbid disorders are factors associated with particular risk. Prevention and reduction of substance abuse, especially of alcohol, must also be a priority. Other risk factors appear to be relationship and financial problems, and to a lesser degree social isolation.

Prevention of access to dangerous methods at times of special risk is important but difficult to achieve as most nurses will have knowledge of dangerous methods that can be acquired outside clinical situations. However, caution in prescribing potentially toxic antidepressants to distressed nurses at risk is clearly important. Particular care should be taken in prescribing of co-proxamol.

The study was supported by a grant from the Department of Health, K. H. and S. S. were also supported by Oxford and Anglia, and South-East Region, NHS Executive Research and Development Committees. K. H. is also supported by Oxfordshire Mental Healthcare NHS Trust. We thank the Office for National Statistics and the coroners, general practitioners, psychiatrists and Family Health Service Authorities who provided information, The Samaritans for advice and financial support for the pro- duction of the Bereavement Information Pack and the Royal College of Nursing and Unison for identifying potential control nurses. We also thank Ann Day for her help with coding and entering data and Jon Allen (Executive Director of Nursing, Oxford Mental Healthcare NHS Trust) for advice. Most importantly, we wish to express our considerable gratitude to the relatives and other informants and the control nurses who participated in the study.

\section{REFERENCES}

Barraclough, B. M., Bunch, J., Nelson, B. \& Sainsbury, P. (1974). A hundred cases of suicide: clinical aspects. British Journal of Psychiatry 12, 355-373.

Beautrais, A. L., Joyce, P. R. \& Mulder, R. T. (1999). Personality traits and cognitive styles as risk factors for serious suicide attempts among young people. Suicide and Life-Threatening Behavior 29, 37-47.

Department of Health (1999). Safer Services: National Confidential Inquiry into Suicide and Homicide by People with Mental Illness. Department of Health: London.

Foster, T., Gillespie, K. \& McClelland, R. (1997). Mental disorders and suicide in Northern Ireland. British Journal of Psychiatry 170, $447-452$.

Hawton, K. \& Vislisel, L. (1999). Suicide in nurses. Suicide and LifeThreatening Behavior 29, 86-95.

Hawton, K., Simkin, S., Malmberg, A., Fagg, J. \& Harriss, L. (1998). Suicide and Stress in Farmers. The Stationery Office: London

Hawton, K., Clements, A., Simkin, S. \& Malmberg, A. (2000). Doctors who kill themselves: a study of the methods used for suicide. Quarterly Journal of Medicine 93, 351-357.

Hemenway, D., Solnick, S. J. \& Colditz, G. A. (1993). Smoking and suicide among nurses. Public Health Briefs 83, 249-251.

Hill, K., Hawton, K., Malmberg, A. \& Simkin, S. (1997). Bereavement Information Pack: for Those Bereaved by Suicide or Other Sudden Death. Royal College of Psychiatrists (Gaskell Press): London. Also available on-line from: http://www.rcpsych.ac.uk/publications/gaskell/bereav/index.htm

Kawachi, I., Willet, W. C., Colditz, G. A., Stampfer, M. J. \& Speizer, F. E. (1996). A prospective study of coffee drinking and suicide in women. Archives of Internal Medicine 156, 521-525.

Kelly, S. \& Bunting, J. (1998). Trends in suicide in England and Wales, 1982-96. Population Trends 92, 29-41.

Kelly, S., Charlton, J. \& Jenkins, R. (1995). Suicide deaths in England and Wales, 1982-92: the contribution of occupation and geography. Population Trends 80, 16-25.

Linehan, M. M., Rizvi, S. L., Welch, S. S. \& Page, B. (2000). Psychiatric aspects of suicidal behaviour: personality disorders. In The International Handbook of Suicide and Attempted Suicide (ed. K. Hawton and K. Van Heeringen), pp. 147-178. Wiley: Chichester

Lönnqvist, J. K. (2000). Psychiatric aspects of suicidal behaviour: depression. In The International Handbook of Suicide and Attempted Suicide (ed. K. Hawton and K. Van Heeringen), pp. 107-120. Wiley: Chichester

Murphy, G. E. (2000). Psychiatric aspects of suicidal behaviour: substance abuse. In The International Handbook of Suicide and Attempted Suicide (ed. K. Hawton and K. Van Heeringen), pp. 135-146. Wiley: Chichester

Sakinofsky, I. (2000). Repetition of suicidal behaviour. In The International Handbook of Suicide and Attempted Suicide (ed. K. Hawton and K. Van Heeringen), pp. 385-404. Wiley: Chichester SPSS Inc. (1999). SPSS Base 9.0 User's Guide. Prentice Hall: New Jersey 
StataCorp. (1999). Stata Statistical Software: Release 6.0. Stata Corporation: College Station, TX

Tyrer, P., Alexander, J. \& Ferguson, B. (1988). Personality Assessment Schedule (PAS). In Personality Disorder: Diagnosis, Management and Course (ed. P. Tyrer), pp. 140-167. Butterworth/

Wright: London
Vale, J. A., Buckley, B. M. \& Meredith, T. J. (1984). Deaths from paracetamol and dextropropoxyphene (distalgesic) poisoning in England and Wales in 1979. Human Toxicology 3, 135S-143S.

World Health Organization (1993). The ICD-10 Classification of Mental and Behavioural Disorders. Diagnostic Criteria for Research. WHO: Geneva. 